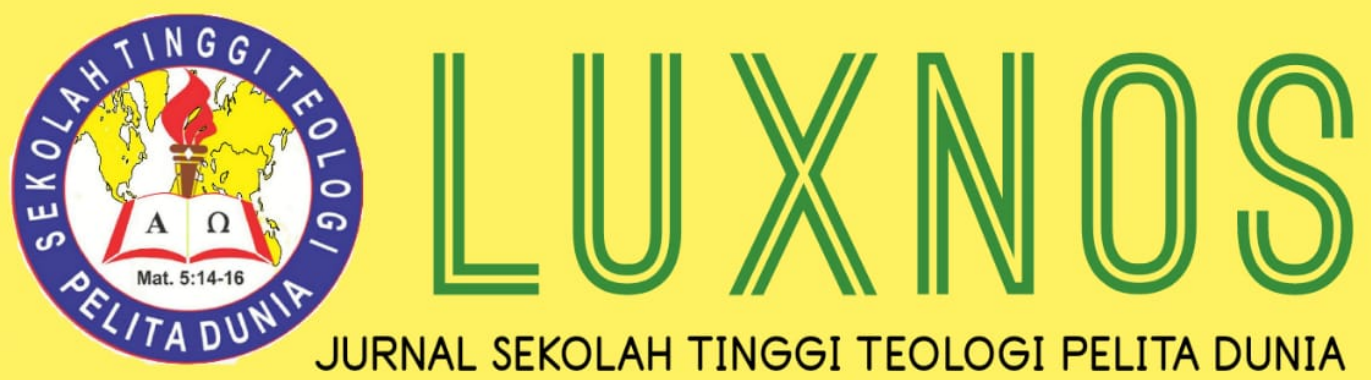

Volume 7 Nomor 2, Desember 2021

P-ISSN : 2527-7561

E-ISSN : 2722-3809

\title{
Dampak Pelaksanaan Persekutuan Doa dan Khotbah Variatif Terhadap Pertumbuhan Iman Jemaat
}

\author{
Hasahatan Hutahaean 1 \\ Sekolah Tinggi Teologi Sumatera Utara \\ hasea2014@gmail.com \\ Gundari Ginting ${ }^{2}$ \\ Sekolah Tinggi Teologi Sumatera Utara \\ gundariginting@gmail.com \\ Marthen Palar ${ }^{3}$ \\ Sekolah Tinggi Teologi Sumatera Utara \\ marthenpalar0@gmail.com \\ Gerhard E. Sipayung ${ }^{4}$ \\ Sekolah Tinggi Teologi Baptis Medan \\ gerhardes@yahoo.com

\section{Desman Josafat Boys ${ }^{5}$} \\ Sekolah Tinggi Teologi Reformed Injili Lumbantor \\ maria.lumbantoruan@yahoo.co.id
}

\begin{abstract}
This research departs from experiences and facts in the field that an interesting and varied sermon needs to be endeavored to attract listeners' interest in worship and for the growth of faith. Apart from that, it is also felt the importance of conducting scheduled prayer meetings with various careful preparations to reap the results among the congregations. The research was conducted at the Indonesian Presbyterian Missi Church (GPMI) Sola Fide Suka Dame congregation, Pancur Batu, with 30 samples selected from all the existing congregations. The method used is quantitative with data and facts from existing events. To collect data, a questionnaire was distributed with structured statements and given a score (scoring). The results showed that the preacher's creativity with various types of sermons (varied) contributed to the growth of the congregation's faith. Likewise, the prayer fellowship had a significant influence on the growth of the congregation's faith.
\end{abstract}

Keywords: worship, varied sermons; prayer meeting, faith growth 


\begin{abstract}
Abstrak: Penelitian ini berangkat dari pengalaman dan fakta di lapangan bahwa khotbah yang menarik perlu diupayakan untuk menarik minat pendengar dalam ibadah serta demi pertumbuhan iman. Di samping itu juga dirasa pentingnya pelaksanaan persekutuan doa secara terjadwal dengan berbagai persiapan yang matang guna menuai hasil diantara jemaat. Penelitian dilakukan di Gereja Presbyterian Missi Indonesia (GPMI) Jemaat Sola Fide Suka Dame, Pancur Batu, dengan 30 orang sampel yang dipilih dari seluruh jemaat yang ada. Metode yang digunakan adalah kuantitatif dengan data serta fakta dari kejadian yang pernah ada. Angket disebar kepada responden yang ditentukan secara acak dari komunitas Persekutuan Doa. Hasil menunjukkan bahwa adanya kreatifitas pengkhotbah dengan berbagai jenis khotbah (variatif) memberikan kontribusi kepada pertumbuhan iman jemaat. Demikian juga persekutuan doa memberikan pengaruh yang signifikan terhadap pertumbuhan iman jemaat. Persekutuan Doa merupakan bagian pelayanan yang penting untuk dipertahankan dalam gereja. Demikian juga memberikan khotbah bervariasi patut diupayakan gereja demi pertumbuhan iman jemaat.
\end{abstract}

Kata Kunci: ibadah, khotbah variatif, persekutuan doa, pertumbuhan iman

\title{
Pendahuluan
}

Memiliki jemaat yang kuat di dalam Tuhan (memiliki iman yang teguh) adalah kerinduan setiap hamba Tuhan atau gembala sidang. Dan ini menjadi tugas bahkan tanggung jawabnya sebagai hamba Tuhan untuk mengembangkan pelayanan yang dipercayakan oleh Tuhan. Sebab pelayanan penggembalaan adalah satu upaya menuntun suatu komunitas atau individu untuk memahami dan menghayati isi hati Tuhan dalam firman-Nya dan dengan kebenaran firman-Nya diharapkan untuk hidup dan menghadapi berbagai pergumulan di dalam Allah. ${ }^{1}$ Tentunya untuk mencapai harapan di atas, seorang hamba Tuhan dalam hal ini gembala perlu membuat programprogram pelayanan yang dapat dilakukan untuk menuntun atau membina jemaat supaya benar-benar takut Tuhan hingga memiliki iman yang kuat. Dalam paparan Sitorus Yeremia, pertumbuhan itu biasanya dipakai untuk menggambarkan hubungan Israel dengan Allah (Yer. 2:3), ${ }^{2}$ dan berkat-berkat kerohanian yang diberikan Allah (Yes .29:19; 40:29), teristimewa pada kedatangan Mesias (Yes. 9:3,7). Maksudnya akses dari pertumbuhan iman itu mengarah kepada hubungan dengan Allah yang kian membaik dalam ibadah, persembahan atau kekudusan hidup umat Israel. Dalam Perjanjian Baru, pertumbuhan itu dipakai menggambarkan perkembangan gereja (1 Kor. 3:6, Ef 2:21, 4:16, Kol. 2:19), dan kebajikan-kebajikan khusus, umpamanya pengetahuan (Kol. 1:10). Pertumbuhan menunjuk kepada bertambahnya jemaat dengan iman yang kian

\footnotetext{
${ }^{1}$ Nathanael Channing, "Anugerah Dalam Pelayanan Penggembalaan," Veritas : Jurnal Teologi dan Pelayanan 3, no. 2 (2002): 193-198.

2 Herowati Sitorus, "Refleksi Teologis Kitab Yeremia Tentang Pesan Sang Nabi Bagi Orang-Orang Buangan," BIA': Jurnal Teologi dan Pendidikan Kristen Kontekstual 1, no. 2 (2018): 267-280, http://www.jurnalbia.com/index.php/bia/article/view/58.
} 
membaik. Sedangkan perkembangan dalam arti bertambahnya jenis pelayanan dan kategorial yang memerlukan perhatian secara khusus.

Dalam pengamatan peneliti jemaat yang rajin berdoa dan sering mendengarkan firman Tuhan memiliki perbedaan pertumbuhan iman bila dibandingkan dengan jemaat yang yang tidak ada persekutuan doa dan mendengar khotbah atau firman Tuhan. Dalam satu penelitian di Palangkaraya menunjukkan pembinaan rohani yang dilakukan misalnya dengan khotbah dan persekutuan doa memberi gairah pertumbuhan iman jemaat dengan pesat ke arah yang lebih baik. ${ }^{3}$ Karena berdoa dan khotbah akan membawa dampak yang positif bagi orang yang mengikutinya. Belum lagi jika penyajian khotbah dipaparkan variatif, sehingga menghindari kebosanan jemaat. Yesus yang berbicara mengenai pertumbuhan Kerajaan Allah (mis. perumpamaan tentang biji sesawi, Mrk. 4:30-32), yang di dalamnya menunjukkan perbedaan kontras antara benih yang amat kecil, hampir tak terlihat, dengan hasil akhirnya. Seperti halnya pertumbuhan terjadi dalam proses yang misterius, tersembunyi, namun pasti, demikian pula Kerajaan Allah akan berkembang dari permulaan yang kecil dalam pelayanan Yesus. Kerajaan Allah sekaligus telah hadir, dan dipahami juga belum hadir secara penuh. Bagi para pembaca Markus, perumpamaan tersebut merupakan dorongan semangat bahwa pada akhir zaman kemuliaan Kerajaan Allah akan ada secara nyata. Prinsip ini sekaligus menghadirkan kebenaran Allah, tuntunan untuk hidup benar sesuai Alkitab, juga memperhatikan apa yang dirasakan oleh jemaat. ${ }^{4}$ Dalam hal ini pertumbuhan iman itu berbicara hubungan antara gereja dan Allah yang tampak dalam kehidupan anggota jemaat. Dalam upaya menumbuhkan iman, bukan semata teologi apa yang hendak digunakan pada satu gereja atau komunitas. Sebab pada hakekatnya teologi mampu melampaui zaman serta berbagai bidang teologi seperti misiologi, pneumatologi atau eklesiologi. ${ }^{5}$ Dalam pengamatan di lapangan Peneliti memperhatikan pertumbuhan iman tampak pada praksis sehari-hari yang menyangkut kehidupan ibadah, doa, melakukan firman Tuhan yang disampaikan dalam khotbah serta turut memenuhi kebutuhan-kebutuhan di gereja atau komunitas tertentu (para church) yang diikutinya.

Dari fakta tersebut diduga ada beberapa perlakuan yang dapat diandalkan untuk meningkatkan pertumbuhan iman jemaat Sedangkan berbicara tentang iman, berarti pasrah menyerahkan diri sendiri tanpa syarat kepada rahmat Allah. Iman berarti

3 Bambang Sriyanto and Thomy Sanggam Hasiholan Sihite, "Peran Gereja Dalam Pembinaan Kerohanian Remaja Di Gereja Pantekosta Di Indonesia Kota Palangka Raya," KHARISMATA: Jurnal Teologi

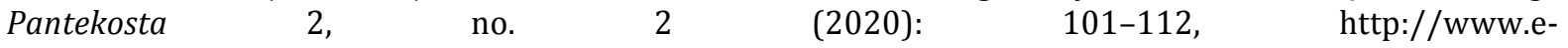
journal.stajember.ac.id/index.php/kharismata/article/view/32/pdf.

${ }^{4}$ Daniel Sutoyo, "Analisis Historis Terhadap Teologi Gerakan Pentakostalisme," DUNAMIS: Jurnal Teologi dan Pendidikan Kristiani 2, no. 2 (2018): 167-196.

5 Harls Evan R. Siahaan, "Presuposisi Kitab Kisah Para Rasul Dalam Rancang Bangun Teologi Pentakosta," Kurios 4, no. 1 (2018): 56-73, https://www.sttpb.ac.id/ejournal/index.php/kurios/article/view/34/48. 
memegang teguh janji Allah di dalam Kristus dengan memautkan seluruh kepercayaan kerpada karya Kristus yang genap seutuhnya demi keselamatan dan kepada kekuasaan Roh Kudus demi kekuatan sehari-hari. Iman mencakup kepercayaan yang utuh dan ketaatan mutlak kepada Allah. Setiap jemaat, ketika menghadapi situasi tidak seperti yang diinginkan, itu adalah masa yang sulit. Dikatakan demikian jika selaku orang percaya, kita tidak mendapatkan kesempatan dekat dengan Tuhan bahkan mengerti akan kebenaran firman Tuhan dengan baik dan benar, sehingga tidak bertumbuh secara kualitas, mereka tidak kuat di dalam Tuhan. Hal itu disebabkan oleh beberapa faktor, termasuk di dalamnya usaha atau pekerjaan, pergaulan atau lingkungan tempat tinggal dan bergaul. Untuk mewujudkan dekat dengan Allah dan memahami firman-Nya butuh kesadaran penuh akan ketergantungan kepada Allah pemilik Firman. Hutahaean menerangkan bahwa Roh Kudus menuntun memberi jaminan dalam usaha-usaha manusia untuk memahami firman-Nya agar jemaat-Nya dekat dengan Allah. ${ }^{6}$

Dengan beberapa penelitian di atas, peneliti melihat ada beberapa sisi dalam pertumbuhan iman yang hendak ditelitu pada jemaat Gereja Presbyterian Missi Indonesia (GPMI) Jemaat "Sola Fide", Kec. Kutalimbaru, Kab. Deli Serdang, Sumatera Utara. Dalam observasi diketahui bahwa jemaat merasa tidak membutuhkan orang lain atau jemaat yang lain sebagai satu tubuh, tidak mau bekerja sama dengan baik. ${ }^{7}$ Jemaat tidak mempraktekkan firman Tuhan dalam kehidupan sehari-hari, dengan alasan mereka malu kalau diperhatikan oleh orang lain. Selanjutnya, Jemaat mudah terpengaruh dengan lingkungan, mereka merasa bahwa pengaruh dari luar seperti lingkungan, kemajuan elektronik dan lain sebagainya itu tidak masalah, akibatnya jemaat tidak mau mengenal dengan baik dan benar siapa itu Yesus yang adalah Tuhan dan Juruselamat. Observasi dari lapangan menunjukkan jemaat tidak ada keterbebanan dalam menyampaikan firman Tuhan, mereka hanya ingin selalu mendengar-mendengar tentang firman Tuhan tetapi tidak mau menyampaikannya kepada orang lain, dalam arti jemaat belum ada keinginan untuk menyampaikan keselamatan yang dia sudah terima dari Tuhan kepada orang-orang yang ada disekitarnya sebagaimana yang diinginkan gembala Agung. Pelayanan penggembalan tidaklah dikerjakan dengan kepandaian atau kemampuan, tetapi dengan kerendahan hati. Demikianlah dengan pertumbuhan iman jemaat, kerendadahan hati juga harus dimiliki. Karena rendah hati adalah kemampuan dan kekuatan sebenarnya bagi orang percaya. Dikatakan sebagai kekuatan karena kerendahan hati itu berbicara bagaimana menyerahkan diri sepenuhnya kepada Tuhan sebagai sumber hidup yang adalah segalanya bagi Tuhan. Dalam hal komunal, itulah yang dikatakan dengan persekutuan doa.

\footnotetext{
6 Hasahatan Hutahaean, Pangimpola Na; Pemahaman Nats-Nats Almanak Dengan Pendekatan Metode BGA (Medan: Prodi Teologi STT-SU, 2017).

7 Majelis GMII Pancurbatu, Wawancara (Medan, 2020).
} 
Dalam Alkitab Edisi Studi, dinyatakan bahwa berdoa berarti berbicara dengan Allah dan mendengarkan-Nya atau memuji Allah dengan perkataan dan nyanyian. Doa pengakuan dimaksudkan untuk mengakui berbagai perbuatan dan pikiran yang keliru, dan doa permohonan bertujuan untuk memohon pertolongan Allah. Doa juga dinaikkan untuk mensyukuri berkat-berkat Allah yang demikian limpahnya misalnya nafas, kesehatan dan kecukupan makan minum. Manusia dapat berdoa kepada Allah sendirian, seperti yang Yesus lakukan (Mat. 14:23). Berdoa sendiri atau bersama-sama dapat dilakukan dengan kata-kata serta berbentuk nyanyian. Juga dapat dipimpin oleh seseorang yang dituakan misalnya Ayah-Ibu atau Kakak tertua yang menjadi juru bicara kepada Allah, mewakili semua yang ada.

Menurut peneliti doa adalah kebaktian mencakup segala sikap roh manusia dalam pendekatannya kepada Allah. Orang yang berdoa dapat menujukkan baktinya kepada Allah jika memberikan puji dan puja, mengakui kebesaran Allah, dengan rendah hati memuji dan mengajukan permohonan kepada-Nya. Doa sebagai perbuatan tertinggi yang dapat dilakukan oleh roh manusia, menjadi bagian dari usahanya terhadap satu tujuan tertentu. Doa dapat dipandang sebagai usaha menjalin persekutuan dengan Allah, dan di dalam doa itu boleh disisipkan membaca Alkitab.

Henri Veldhuis menyatakan bahwa doa begitu hakiki bagi iman, di dalam gereja, juga di dalam rumah dan dalam konteks lainnya. Berdoa adalah membuka hati anda bagi Allah dan berbicara kepada-Nya, atau anda diam untuk mendengarkan Dia. Berdoa dapt dilakukan dengan bersuara pelan, seuara keras atau di dalam hatidan disertai dengan menyanyi. Anda dapat berdoa dimana-mana, di dalam gereja atau ketika sedang naik sepeda. Doa muncul dari keinginan akan Allah; anda juga dapat mengalaminya jika anda berdiam diri. ${ }^{8}$ Dapat dipahami bahwa doa adalah bagaimana orang percaya merendahkan diri dihadapan Allah dalam segala situasi dan dimanapun berada, bahkan doa itu adalah salah satu cara bagi manusia mengakui Tuhan itu segalanya.

Dari mulanya Allah memang berkehendak menolong kita; namun karena Ia sangat senang dengan doa-doa yang dipanjatkan anak-anak-Nya. Ia membiarkan kita berdoa begitu lama; selain untuk menguji iman kita, Ia juga hendak membuat jawabanNya sebagai momen yang terindah. ${ }^{9}$ George Muller pernah mengajarkan untuk terus berdoa karena orang yang berdoa adalah orang yang menemukan jawaban indah. Karena ada anggapan bahwa pencobaan atau masalah sebagai penghalang untuk bertumbuh. Karena itu Paulus mengingatkan orang percaya untuk mengerti kedudukannya sebagai jemaat di tengah-tengah dunia. Paulus berbicara mengenai bagaimana harus hidup di tengah-tengah dunia ini. Sebagaimana yang dikatakannya dalam 1 Korintus 10:13-15, bahwa pencobaan tidak akan melebihi kekuatan manusia

\footnotetext{
${ }^{8}$ Henri Veldhuis, Kutahu Yang Kupercaya (Jakarta: BPK Gunung Mulia, 2010).

${ }^{9}$ Ibid.
} 
bahkan Tuhan tidak akan membiarkan kita dicobai melebihi kekuatan kita. Dalam hal ini dapat dinyatakan bahwa gereja yang ideal ditandai oleh pertumbuhan yang serasi dalam arti jumlah anggotanya bertambah karena mutu kehidupan iman anggotanya makin mendalam dan kokoh berakar di dalam Kristus, firman yang hidup itu. Keadaan ini hanya dapat dicapai jika kehidupan doa anggotanya, baik secara pribadi maupun secara kelompok mendapat prioritas utama dan diberikan peran yang menggerakan dan menentukan. Bahkan dengan singkat disebut juga bahwa pertumbuhan gereja itu dimulai dari doa dan mencari hikmat Allah juga dengan doa. ${ }^{10}$

Selanjutnya berbicara pengajaran firman Tuhan (Khotbah), harus disampaikan dengan baik dengna memperhatikan pendengar atau komunikan. ${ }^{11}$ Upaya untuk menjelaskan nats Alkitab khotbah agar mudah dimengerti pendengar, pada umumnya adalah keinginan banyak pengkhotbah. Sebagaimana harus diketahui bahwa di dalam gereja, khotbah itu mempunyai tempat yang sentral, karena tugas Gereja yang utama ialah mengabarkan Firman Tuhan di dalam dunia. Tugas dan kesaksian Gereja tidak terdiri atas perkataan saja (kerygma dan didache), tetapi dalam bentuk persekutuan (koinonia) dan pelayanan (diakonia), di mana dalam kegiatan-kegiatan itu pekabaran Injil adalah tugas yang utama daripada jemaat sebagai saksi-saksi di dunia demi Kristus. Hal ini menjelaskan kepada kita bahwa khotbah besar pengaruhnya dalam pertumbuhan iman jemaat. Sebagaimana bisa kita pahami bahwa khotbah yang variatif juga sebagai motivasi sehingga mereka cenderung menjadi pribadi yang takut akan Tuhan. Karena kehidupan beragama masih banyak dipengaruhi struktur dan kebiasaan hidup lama dengan mementingkan hal-hal yang tampak bukan pada iman dan wujudnya di kehidupan nyata. Sehingga jarang orang bersikap kritis malah skeptis terhadap agama yang mereka anut. Mereka lebih besar dipengaruhi roh daging daripada Roh Tuhan.

Berhubungan dengan pertumbuhan iman jemaat tak dapat disangkal yaitu penyajian-penyajian khotbah yang variatif, dengan memperhatikan relevansi dan kemampuan pendengar untuk melakukan isi firman Tuhan. ${ }^{12}$ Di zaman sekarang ini para pengkhotbah dituntut untuk dapat merebut antusias jemaat agar tertarik mendengarkan khotbah. Ada banyak variasi khotbah sekarang ini baik dari segi penyampaian, maupun dari segi media penyampaian yang dengan harapan adalah firman Tuhan dapat sampai dan diterima oleh jemaat dengan baik. Karena firman Tuhan adalah hal yang lebih inti untuk ditanamkan dalam diri jemaat sebagai panduan hidup agar bertumbuh dengan baik. Dalam ibadah minggu khotbah dapat juga disebut

\footnotetext{
${ }^{10}$ Neil T. Anderson, Menjadi Gereja Pembuat Murid (Yogyakarta: Yayasan Gloria, 2016).

${ }^{11}$ Daniel Ronda and Yonatan Salong, "Analisis Peran Teori Komunikasi Untuk Mencapai Tujuan Khotbah Yang Komunikatif Di Gereja Kibaid Klasis Makassar," Jurnal Jaffray 10, no. 1 (2012): 174-201, https://ojs.sttjaffray.ac.id/JJV71/article/view/70/pdf_51.

12 Mary S Hulst, Pedoman Khotbah Lengkap: Sepuluh Cara Praktis Untuk Khotbah Yang Lebih Baik (Jakarta: Waskita Publishing, 2018).
} 
sebagai pusat berita firman Allah. Sebagai media penyampaian firman Allah, khotbah dapat disampaikan dalam media digital atau rekaman dalam keadaan darurat (atau pandemik) agar kebaktian ${ }^{13}$ di gereja tidak kehilangan inti pemberitaan firman.

Berdasarkan analisa peneliti terhadap teori yang diuraikan di atas, dapat dipahami, pertumbuhan iman itu berbicara hubungan antara gereja dan Allah. Dalam hal ini orang yang sudah percaya dituntut supaya bisa bertumbuh bahkan menghasilkan buah berdasarkan firman Tuhan. Artinya sejak seseorang percaya dan menerima Yesus Kristus secara pribadi (dilahirkan baru), maka orang tersebut harus bertumbuh di dalam iman melalui berbagai proses sehingga bisa menghasilkan buah melalui kesaksian hidupnya. Dia harus hidup di dalam firman, sehingga tidak muda diombangambingkan oleh pengajaran-pengajaran yang menyesatkan. Dalam gerakan pentakosta, Rifai menyatakan bahwa pengajaran pemberitaan injil dengan sepenuhnya adalah sama dengan membawa kembali ajaran yang benar yang telah lama ada diantara jemaat. ${ }^{14}$ Dengan latar belakang situasi diatas, peneliti melihat pertumbuhan iman yang terjadi di tengah jemaat dipengaruhi oleh kegiatan regular seperti persekutuan doa rutin yang dilaksanakan. Berkaitan dengan hal itu, khotbah-khotbah yang monoton menjadi satu permasalahan khusus dalam mengupayakan pertumbuhan iman. Karena itu gereja perlu mengupayakan agar para pemberita Firman yang terjadwal agar menyajikan Firman Tuhan dalam khotbah yang bervariasi. Penelitian ini menduga adanya kontribusi yang berarti dari khotbah variatif terhadap pertumbuhan iman jemaat. Tulisan ini akan mengungkap signifikansi khotbah dan persekutuan doa bagi pertumbuhan iman jemaat.

\section{Metode Penelitian}

Penelitian ini menggunakan metode kuantitatif dengan menjaring data dari kuesioner atau angket ${ }^{15}$ dimana jawaban-jawaban dari responden ditabulasi menjadi berupa angka-angka. ${ }^{16}$ Sesuai teori Sugiyono, maka wawancara untuk mengumpulkan data delakukan dengan pertanyaan terstruktur, ${ }^{17}$ di mana jawaban sangat setuju skor empat (4) hingga sangat tidak setuju skor satu (1). Dalam menjaring data, peneliti menyebar angket kepada responden. Data yang masuk kemudian ditabulasi, untuk

13 Hasahatan Hutahaean, Bonnarty Steven Silalahi, and Linda Zenita Simanjuntak, "Spiritualitas Pandemik: Tinjauan Fenomenologi Ibadah DI Rumah," Evangelikal: Jurnal Teologi Injili dan Pembinaan $\begin{array}{llllll}\text { Warga Jemaat } & 4, & \text { no. } & 2 & \text { (2020): } & \text { 234-249, }\end{array}$ https://journal.sttsimpson.ac.id/index.php/EJTI/article/view/270.

14 Eliezer Rifai, “Analisi Kritis Ajaran 'Rhema' Dan 'Logos' Dalam Perspektif Kaum Pentakosta," DUNAMIS: Jurnal Penelitian Teologi dan Pendidikan Kristiani 1, no. 1 (2016): 88-102.

15 Salim Salim and Haidir Haidir, Penelitian Pendidikan; Metode, Pendekatan, Dan Jenis, ed. Ihsan Satrya Azhar (Jakarta: Kencana Prenada Media Group, 2019), 98-99.

16 Whidmurni Whidmurni, "Penelitian Kuantitatif," Pemaparan Metode Penelitian Kuantitatif 2, no. 16 (2017): 1-16, http://repository.uin-malang.ac.id/1985/2/1985.pdf.

17 Sugiyono Sugiyono, Metode Penelitian Kuantitatif (Bandung: AlfaBeta, 2018). 
diolah, serta ditafsirkan, kemudian hasilnya dipergunakan untuk menarik kesimpulan dari penelitian yang dilakukan oleh peneliti. Sampel dari keseluruhan 120 jumlah Jemaat Gereja Presbyterian Missi Indonesia (GPMI) Jemaat Sola Fide Suka Dame, di Pancur Batu, dengan teori sampling dari Sugiyono ${ }^{18}$ maka sebanyak 30 orang dijadikan sampel dalam penelitian ini. Data berupa ex post facto $^{19}$, dimana data masuk berupa kejadian yang telah berlangsung pada Maret sampai Mei 2019. Angket disebar sesuai dengan yang telah dipersiapkan dari variabel penelitian, yakni pertumbuhan iman, persekutuan doa dan khotbah variatif. Untuk memudahkan pengenalan terhadap variabel maka diberikan penamaan yakni; variabel $\mathrm{X}_{1}$ (Persekutuan Doa) variabel $\mathrm{X}_{2}$ (Khotbah Variatif) dan variabel Y (Pertumbuhan Iman). Masing-masing variabel memiliki 30 butir pernyataan, dengan jawaban yang terstruktur, telap dipersiapkan. Instrumen untuk upaya tersebut dibuat berjenjang dengan turunan nilai/skor berbentuk pilihan dengan empat jawaban.

\section{Hasil dan Pembahasan \\ Data Penelitian dan Hasil}

Berdasarkan data yang masuk dan perhitungan data, maka hasil perhitungan dengan kecenderungan data tiap-tiap variabel penelitian adalah sebagai berikut pertama, uji kecenderungan variabel $\mathrm{X}_{1}$ (Persekutuan Doa) di atas, maka dapat dikategorikan pada kategori baik. Hal ini dibuktikan bahwa dua kategori kelas atas memiliki nilai persentase yang lebih besar yaitu kelas 1 dengan f0 = 12 (40\%) dan kelas 2 dengan f0 $=9$ (20\%). Jika dibandingkan dengan kategori interval kelas bawah di mana kelas 3 dengan f0 =6 (20\%) dan kelas 4 dengan f0 = $3(10 \%)$. Dengan demikian, maka dapat disimpulkan bahwa kecenderungan nilai variabel $\mathrm{X}_{1}$ adalah cenderung Baik (40 $\%$ ). Kedua, uji kecenderungan variabel $\mathrm{X}_{2}$ (Khotbah Variatif) di atas, maka dapat dikategorikan pada kategori baik. Hal ini dibuktikan bahwa dua kategori kelas atas memiliki nilai persentase yang lebih besar yaitu kelas 1 dengan f0 = 17 (57\%) dan kelas 2 dengan f0 = 7 (23\%). Jika dibandingkan dengan kategori interval kelas bawah di mana kelas 3 dengan f0 =3 (10\%) dan kelas 4 dengan f0 = $3(10 \%)$. Dengan demikian, maka dapat disimpulkan bahwa kecenderungan nilai variabel $\mathrm{X}_{2}$ adalah cenderung Baik (57\%). Ketiga nilai uji variabel Y (Pertumbuhan Iman) di atas, maka dapat dikategorikan pada kategori baik. Dengan demikian, maka dapat disimpulkan bahwa kecenderungan nilai variabel $Y$ adalah cenderung Baik (67\%).

Uji normalitas terhadap variabel $\mathrm{X}_{1}$ (Persekutuan Doa) diperoleh nilai Chi $^{2}{ }_{\text {hitung }}=$ $(7,48)<$ Chi2 tabel $(11,07)$. Uji normalitas variabel $X_{2}$ (Khotbah Variatif) di atas diperoleh nilai Chi²hitung $=(8,54)<$ Chi2 2tabel $(11,07)$. Dan uji normalitas variabel $Y$

18 Ibid.

19 Anthony A. Braga, David M. Hureau, and Andrew V. Papachristos, "An Ex Post Facto Evaluation Framework for Place-Based Police Interventions," Evaluation Review 35, no. 6 (2012): 592-626. 
(Pertumbuhan Iman) di atas diperoleh nilai $\mathrm{Chi}^{2}{ }_{\text {hitung }}=(8,35)<$ Chi2 2 tabel $(11,07)$, ketiganya terdistribusi normal.

Dari uji regresi sederhana dan uji linieritas $\mathrm{Y}$ (Pertumbuhan Iman) atas $\mathrm{X}_{1}$ (Persekutuan Doa) diperoleh nilai $F_{\text {hitung }}$ adalah 23, 49. Sementara harga $F_{\text {tabel }}$ pada taraf signifikan $5 \%$ dan derajat kebebasan $(\mathrm{dk})=1: 30$ adalah $(4,17)$, maka harga $\mathrm{F}_{\text {hitung }}$ $(23,49)>$ Ftabel $(4,17)$. Dengan demikian maka dapat disimpulkan bahwa koefisien arah regresi $\mathrm{Y}$ ke $\mathrm{X}_{1}$ adalah Berarti. Dalam perhitungan nilai keberartian, di mana nilai $F_{\text {hitung }}$ adalah 82,60. Sementara uji regresi sederhana dan uji linieritas $Y$ (Pertumbuhan Iman) atas $\mathrm{X}_{2}$ (Khotbah Variatif) harga $\mathrm{F}_{\text {tabel }}$ pada taraf signifikan 5\% dan derajat kebebasan $(\mathrm{dk})=1: 30$ adalah $(4,17)$, maka harga $F_{\text {hitung }}(82,60)>F_{\text {tabel }}(4,17)$. Dengan demikian maka dapat dinyatakan bahwa koefisien arah regresi $\mathrm{Y}$ ke $\mathrm{X}_{2}$ adalah Berarti.

Berdasarkan daftar distribusi t pada taraf signifikan 5\% dengan $\mathrm{dk}=\mathrm{N}-2=28$, didapatkan nilai $t_{\text {tabel }}$ pada taraf tersebut sebesar 1,701. Dengan demikian maka harga $t_{\text {hitung }}(6,5)>t_{\text {tabel }}(1,701)$, dengan demikian dapat disimpulkan bahwa terdapat hubungan yang berarti antara variabel $\mathrm{X}_{1}$ (Persekutuan Doa) dengan variabel $\mathrm{Y}$ (Pertumbuhan Iman). Dari daftar distribusi t pada taraf signifikan 5\% dengan $\mathrm{dk}=\mathrm{N}-2$ $=28$, didapatkan nilai ttabel pada taraf tersebut sebesar 1,701. Dengan demikian maka harga thitung $(9,12)>t_{\text {tabel }}(1,701)$. Dari perolehan hasil ini, dapat disimpulkan bahwa terdapat hubungan yang berarti antara variabel $\mathrm{X}_{2}$ (Khotbah Variatif) dengan variabel Y (Pertumbuhan Iman). Dari perhitungan korelasi ganda antara variabel $\mathrm{X}_{1}$ (Persekutuan Doa) dan variabel $\mathrm{X}_{2}$ (Khotbah Variatif) berhubungan secara bersama-sama dengan variabel Y (Pertumbuhan Iman), diperoleh nilai dari R2y1.2 adalah 0,32. Dari nilai R2y1.2 tersebut, maka koefisien determinasinya adalah 10,24\%. Dari perhitungan ini,

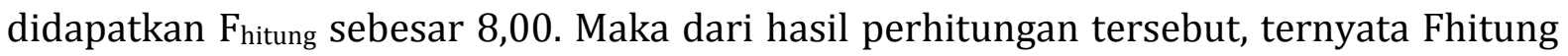
$(8,00)>F_{\text {tabel }}(3,35)$. Dari perolehan hasil ini, dapat disimpulkan bahwa koefisien korelasi ganda adalah berarti dan terdapat hubungan yang berarti antara variabel $\mathrm{X}_{1}$ (Persekutuan Doa) dan variabel $\mathrm{X}_{2}$ (Khotbah Variatif) secara bersama-sama dengan variabel Y (Pertumbuhan Iman).

Pertumbuhan iman yang terjadi di jemaat (sampling) memiliki proses yang tidak terjadi begitu saja. Dalam penelitian menunjukkan bahwa proses pelayanan melalui persekutuan doa yang diadakan secara rutin di tengah jemaat memberikan dampak yang berarti terhadap pertumbuhan imannya. Sedangkan khotbah variatif tidak saja menjadi skill semata, tetapi memberi kontribusi yang berarti dalam pertumbuhan iman jemaat, pendengar khotbah-khotbah variatif. Dua variabel (kegiatan persekutuan doa dan upaya khotbah variatif di jemaat) menjadi elemen penting yang patut diperhatikan oleh gereja dalam memajukan iman jemaat. 


\section{Pembahasan Hasil Penelitian}

\section{Pertumbuhan Iman}

Berdasarkan analisa menunjukkan adanya pertumbuhan berarti dalam diri jemaat yang pasti dan dirasakan atas khotbah yang didengar dan disajikan bervariasi di Gereja. Dengan adanya persekutuan doa yang rutin serta terjadwal menolong jemaat dalam hidup yang penuh penyerahan kepada Tuhan. Temuan itu sejalan dengan yang pernah dituliskan bahwa iman menurut Perjanjian Lama, menjelaskan bahwa iman adalah kesetiaan dihadapan Allah, ketaatan sekaligus juga kepercayaan, yakni penyerahan kepada kesetiaan Allah. Dengan demikian kata "iman" secara harafiah dapat diartikan sikap atau respon manusia terhadap perbuatan Allah yang ditandai dengan kesetiaan, kesungguhan dan ketetapan hati. ${ }^{20}$ Sedangkan iman berdasarkan Perjanjian Baru itu adalah bukti dan jaminan yang paling kokoh bahwa segala sesuatu yang tidak kita lihat merupakan kenyataan yang dinyatakan oleh Tuhan karena dalam pelayanan penggembalaan dibutuhkan bukan hanya berbicara tentang kuantitas umatNya tetapi yang terutama kualitas iman jemaat-Nya

Hukum dari iman itu adalah kebenaran Allah atau firman Tuhan itu sendiri. Karena firman Tuhan itulah yang sanggup mengubahkan manusia untuk hidup dalam kehendak-Nya. Dari hal ini dapat dipaparkan bagai satu kompetisi atau pertandingan. Dalam satu pertandingan, sudah pasti setiap peserta ingin untuk meraih siapa yang terbaik. Untuk menjadi yang terbaik sudah barang tentu dia harus mengalahkan lawanlawannya. Dalam perjalanan kehidupan orang percaya, sebenarnya kita itu juga sementara bertanding. Bertanding yang dimaksud adalah pertandingan iman. Dalam pertandingan ini ada musuh sebagai penghalang dari iman kita, musuh-musuh tersebut adalah misalnya kegagalan untuk memahami arti menjadi ciptaan baru dan kegagalan memahami kebenaran Allah dalam Alkitab.

Dalam penelitian di Gereja Presbyterian Missi Indonesia (GPMI) Jemaat "Sola Fide" Suka Dame, Kec. Kutalimbaru, Kab. Deli Serdang, peneliti bisa melihat ada tiga hambatan pertumbuhan iman diantaranya: pertama, jemaat mencoba berhasil dengan memisahkan diri dari tubuh Kristus. Mereka tidak menyadari sebagai orang percaya adalah satu tubuh, sebagaimana dengan rasul Paulus tulis dalam 1Korintus 12:12, 1827, "Memisahkan diri dari tubuh Kristus." Dalam hal ini ditujukan kepada berbagai kegiatan keseharian yang dapat berakibat pada hidup berdosa, tidak kudus. ${ }^{21}$ Kedua, jemaat gagal mengintegrasikan Kristus dalam setiap segi kehidupan mereka. Karena takut terhadap apa pendapat atau apa yang akan dikatakan teman-teman mereka yang

20 Hasahatan Hutahaean, “Implementasi Keyakinan Telah Diselamatkan," in Proceeding Soteriologi Biblika, ed. Gundari Ginting, Thomas Pandawa Tarigan, and Hasahatan Hutahaean (Medan: Prodi Teologi STT-SU, 2013), 41-56.

21 Zulkisar Pardede, "Rancang Bangun Teologi 'Kekudusan' Tentang Hamba Tuhan Sebagai Pemimpin Kristen Menurut Kitab Yosua,” KHARISMATA: Jurnal Teologi Pantekosta 1, no. 2 (2019): 100117, http://www.e-journal.stajember.ac.id/index.php/kharismata/article/view/20/8. 
belum diselamatkan bila melihat pribadi rohani mereka. ${ }^{22}$ Bahkan orang percaya yang bertumbuh adalah ketika saudara ada di dalam Kristus barulah Kristus ada di dalam saudara karena ketika ada di dalam Kristus barulah saudara akan mengalami kuasa-Nya dalam hidup ini (Kol. 2:6, 7). Dan ketiga, jemaat meremehkan pengaruh dari luar terhadap pertumbuhan mereka dalam kasih karunia Allah. Di mana rasul Paulus katakan; janganlah kamu sesat: pergaulan yang buruk merusakkan kebiasaan yang baik (1 Kor. 15:33). Bagi peneliti, persahabatan hakikatnya harus dapat menjadi bagian untuk mendekatkan diri kepada Allah. Meskipun menjalin hubungan dengan orang di luar Kristen, tidak mengurangi kekuatan dan semangat hidup bagi Kristus. ${ }^{23}$

Berdasarkan analisa peneliti terhadap fakta tersebut yang diuraikan para ahli di atas, yang dikatakan musuh dari iman adalah ketidakmengertian akan hidupnya sebagai orang percaya. Dikatakan orang beriman tetapi tidak melakukan apa yang dikehendaki oleh Tuhan atau tidak hidup dalam iman. Hidup yang tidak menyadari bahwa dia sudah diampuni (diselamatkan), berarti musuh dari iman sesungguhnya adalah dirinya sendiri selaku orang percaya, dimana hidupnya dikendalikan oleh roh daging bukan Roh Kudus.

\section{Persekutuan Doa}

Selain menjadikan doa sebagai prioritas utama di gereja, maka untuk mengadakan gerakan doa di gereja, pendeta dan para pejabat gereja harus mempunyai visi bahwa keikutsertaan para anggota dalam pelayanan doa itu sangat penting. Mereka harus mampu melihat peranan mereka berdasarkan Efesus 4:11-13, khusunya “...untuk memperlengkapi orang-orang kudus bagi pekerjaan pelayanan...” Pendeta juga harus menjadi teladan dalam kehidupan doanya, kepemimpinannya, dan keterlibatannya. Gereja akan bertumbuh seimbang dan anggotanya berbuah lebat jika doa dijadikan prioritas utama dalam gereja. Firman Allah di Yesaya 56:7 menyatakan, “...sebab rumah-Ku akan di sebut rumah doa bagi segala bangsa."

Yesus sendiri mengutip firrman ini ketika Ia mengusir orang-orang yang berjual beli di halaman bait Allah (Mark. 11:17). Jadi rumah Allah bukan rumah penginjilan, atau rumah penyembahan, atau rumah pertemuan, melainkan rumah doa. Fungsi utama gereja dalam arti bait Allah adalah untuk berdoa, juga gereja dalam arti gedung (tempat berdoa) maupun anggota gereja sebagai pribadi dan persekutuan doa (1Kor. 3:16).

Dari pemaparan ini, dapat dimengerti bahwa berdoa memiliki kuasa untuk mengubahkan orang yang sedang berdoa tersebut. Setiap orang memiliki tempattempat persembunyian dalam dirinya yang tidak ingin agar orang lain ketahui, karena

22 Andrew Williams, "Spiritual Landscapes of Pentecostal Worship, Belief, and Embodiment in a Therapeutic Community: New Critical Perspectives," Emotion, Space and Society 19, no. 1 (2016): 45-55.

23 Yohanes Krismantyo Susanta, “'Menjadi Sesama Manusia’ Persahabatan Sebagai Tema Teologis Dan Implikasinya Bagi Kehidupan Bergereja," DUNAMIS: Jurnal Teologi dan Pendidikan Kristiani 2, no. 2 (2018): 103-118, https://sttintheos.ac.id/e-journal/index.php/dunamis/article/view/169/132. 
didalamnya terdapat perbuatan-perbuatan yang dilakukan yang tidak sesuai kehendak Allah. Dan dengan doa sungguh-sungguh Allah akan mengubahkan dan mengeluarkan kita dari tempat tersebut. Begitu pula di dalam gereja, yang menjadi penyebab orang percaya tidak bertumbuh, sering karena jemaat-jemaat di dalamnya belum diubahkan hidup mereka. Ini ibarat tanaman tidak akan bertumbuh dengan baik jika ada hama yang menggerogotinya. Gereja tidak akan bertumbuh kalau pribadi-pribadi di dalamnya masih menyimpan hama yang merusak kerohaniannya secara pribadi.

\section{Khotbah Yang Variatif}

Sebagaimana dalam bagian awal peneliti sampaikan bahwa, berhubungan dengan pertumbuhan iman jemaat tak dapat disangkal yaitu penyajian-penyajian khotbah yang variatif. Karena itu para pengkhotbah dituntut untuk dapat merebut antusias jemaat agar tertarik mendengarkan khotbah. Ada banyak variasi khotbah sekarang ini baik dari segi penyampaian, maupun dari segi media penyampaian yang dengan harapan adalah Firman Tuhan dapat sampai dan di terima oleh jemaat dengan baik. Karena itu Hasan Susanto mengatakan, apabila berita dari mimbar tidak mantap dan goyah, maka gereja lemah; apabila mimbar menyajikan berita yang pasti, dan tegas, maka gereja kuat. Dalam kata pengantar sebuah buku, Indrasmoro menyatakan bahwa khotbah yang variatif atau perlu karena sangat efektif untuk pertumbuhan jemaat. Untuk menolong pengkhotbah dalam menarik perhatian pendengar. ${ }^{24} \mathrm{Hal}$ ini dimaksudkan agar keseriusan muncul serta ketertarikan ada dari pendengar. Berarti khotbah dan jemaat sangat berkaitan dalam pertumbuhan gereja. Agar khotbah memperoleh dampak langsung kepada pendengar-pendengarnya, khotbah itu barus bebas dari ketidakjelasan dan tidak berisi materi tambahan yang tidak ada hubungan dengan tema utama.

Satu hal yang penting dalam khotbah yakni si pengkhotbah sendiri, dalam hal perilakunya, kesaksian pribadi, dan rumah tangganya. Pengkhotbah harus memiliki kredibilitas yang tinggi, pribadi dan keluarga. Bagi pengkhotbah sekaligus gembala jemaat bagian ini akan kelihatan setiap hari di jemaat. Sebab pendeta sekaligus gembala berada di tengah jemaat atau pastori yang disediakan gereja. Disamping itu, kharisma harus seimbang dengan karakter. Pengkhotbah adalah panutan dan teladan bagi jemaat (1Kor. 4:15-16). Pemberitaan Firman Allah haruslah memiliki keberanian dan tidak bergantung pada situasi dan kondisi (Kis. 4:29, II Tim. 3:2). Dalam konteks pengkhotbah sebagai gembala sidang atau pemimpin jemaat atau majelis jemaat yang memiliki tugas dan tanggung jawab untuk memelihara domba Allah, maka hendaklah pengkhotbah memiliki hubungan yang intim, harmonis dan saling terbuka dengan jemaat. Kehidupan

${ }^{24}$ Greg Scharf, Khotbah Yang Transformatif (Jakarta: Yayasan Komunikasi Bina Kasih, 2013). 
sehari-hari ini juga dapat memacu semangat jemaat untuk mengikuti berbagai persekutuan doa yang diselenggarakan oleh gereja.

Sebab akibat dari hubungan dengan jemaat, pengkhotbah dapat memahami pergumulan hidup jemaat, kebutuhan rohani jemaat. Dengan demikian pengkhotbah dapat mengarahkan aplikasi khotbahnya terhadap pergumulan dan kebutuhan jemaatnya. Dan juga melalui hubungan dan interaksi yang baik antara jemaat dan pendeta, pengkhotbah dapat melihat, memantau efektivitas khotbah dalam kehidupan sehari-hari. Sehingga pengkhotbah juga bisa mengerti bagaimana menyajikan atau menyampaikan khotbah dengan demikian dapat memaksimalkan untuk menarik antusias jemaat.

Alkitab mengajarkan bahwa pelaksanaan Persekutuan Doa harus selalu diajarkan dan tidak boleh diabaikan setiap orang percaya. Bahkan mengingatkan kita, terkabulnya doa-doa bukan didasarkan pada pengajuan permohonan kita, tetapi bagaimana ketaatan akan perintah Tuhan yaitu memiliki kehidupan doa dalam mengahadapi situasi-situasi apapun yang terjadi dalam hidup ini dengan tujuaniman dapat bertumbuh. Jadi dapat dipahami bahwa doa adalah benar dikatakan nafas hidup orang yang beriman kepada Yesus.

Dalam hal ini orang percaya (jemaat Gereja) harus menyadari bahwa tanpa doa kita akan mati secara rohani, Karena orang percaya yang tidak berdoa tidak akan bertumbuh dalam mengikut Tuhan. Sebab itu jemaat dituntut untuk hidup dalam doa, bahkan di tengah-tengah gereja di mana digembalakan harus selalu ikut ambil bagian dalam setiap program yang sudah diadakan oleh organisasi gereja yang ada dalam kaitannya dengan persekutuan doa. Kegiatan persekutuan doa memberikan pengalaman spiritual kepada pesertanya dalam penyerahan diri yang kian sungguhsungguh. Demikian juga upaya menyajikan khotbah secara variatif memberikan hasil yang berarti bagi pertumbuhan iman jemaat.

\section{Kesimpulan}

Dari penelitian ini dapat dinyatakan bahwa persekutuan doa dan penyajian khotbah secara variatif mempunyai pengaruh yang signifikan terhadap pertumbuhan iman jemaat. Demikian juga dalam penyajian khotbah memiliki daya tarik tersendiri bagi jemaat untuk mendengarkan, sehingga terjadi kerinduan-keinginan untuk datang ke gereja dalam ibadah atau mengikuti persekutuan doa. Pertumbuhan iman menjadi diskusi penting bagi keberlanjutan keberadaan gereja ke depan jika tidak ingin menjadi rapuh. Dengan penelitian ini diharapkan ada penelitian lanjutan untuk mendalami diskusi pada ranah penyusunan khotbah variatif sesuai dengan kategorial pendengar. Sebab kian hari dan semakin beragamnya jemaat maka varian untuk dewasa misalnya, mungkin tidak cocok bagi jemaat kategorial millennial atau post-millenial. Bahkan dapat 
dilanjutkan dengan penelitian dan kegiatan masyarakat untuk memberi pendampingan pelatihan khotbah yang variatif.

\section{Referensi}

Anderson, Neil T. Menjadi Gereja Pembuat Murid. Yogyakarta: Yayasan Gloria, 2016.

Braga, Anthony A., David M. Hureau, and Andrew V. Papachristos. "An Ex Post Facto Evaluation Framework for Place-Based Police Interventions." Evaluation Review 35, no. 6 (2012): 592-626.

Channing, Nathanael. "Anugerah Dalam Pelayanan Penggembalaan." Veritas: Jurnal Teologi dan Pelayanan 3, no. 2 (2002): 193-198.

Hulst, Mary S. Pedoman Khotbah Lengkap: Sepuluh Cara Praktis Untuk Khotbah Yang Lebih Baik. Jakarta: Waskita Publishing, 2018.

Hutahaean, Hasahatan. "Implementasi Keyakinan Telah Diselamatkan.” In Proceeding Soteriologi Biblika, edited by Gundari Ginting, Thomas Pandawa Tarigan, and Hasahatan Hutahaean, 41-56. Medan: Prodi Teologi STT-SU, 2013.

- - - Pangimpola Na; Pemahaman Nats-Nats Almanak Dengan Pendekatan Metode $B G A$. Medan: Prodi Teologi STT-SU, 2017.

Hutahaean, Hasahatan, Bonnarty Steven Silalahi, and Linda Zenita Simanjuntak. "Spiritualitas Pandemik: Tinjauan Fenomenologi Ibadah DI Rumah." Evangelikal: Jurnal Teologi Injili dan Pembinaan Warga Jemaat 4, no. 2 (2020): 234-249. https://journal.sttsimpson.ac.id/index.php/EJTI/article/view/270.

Majelis GMII Pancurbatu. Wawancara. Medan, 2020.

Pardede, Zulkisar. "Rancang Bangun Teologi 'Kekudusan' Tentang Hamba Tuhan Sebagai Pemimpin Kristen Menurut Kitab Yosua." KHARISMATA: Jurnal Teologi Pantekosta 1, no. 2 (2019): 100-117. http://www.ejournal.stajember.ac.id/index.php/kharismata/article/view/20/8.

Rifai, Eliezer. "Analisi Kritis Ajaran 'Rhema' Dan 'Logos' Dalam Perspektif Kaum Pentakosta.” DUNAMIS: Jurnal Penelitian Teologi dan Pendidikan Kristiani 1, no. 1 (2016): 88-102.

Ronda, Daniel, and Yonatan Salong. "Analisis Peran Teori Komunikasi Untuk Mencapai Tujuan Khotbah Yang Komunikatif Di Gereja Kibaid Klasis Makassar." Jurnal Jaffray 10, no. 1 (2012): 174-201. https://ojs.sttjaffray.ac.id/JJV71/article/view/70/pdf_51.

Salim, Salim, and Haidir Haidir. Penelitian Pendidikan; Metode, Pendekatan, Dan Jenis. Edited by Ihsan Satrya Azhar. Jakarta: Kencana Prenada Media Group, 2019.

Scharf, Greg. Khotbah Yang Transformatif. Jakarta: Yayasan Komunikasi Bina Kasih, 2013.

Siahaan, Harls Evan R. "Presuposisi Kitab Kisah Para Rasul Dalam Rancang Bangun Teologi Pentakosta." Kurios 4, no. 1 (2018): 56-73. https://www.sttpb.ac.id/ejournal/index.php/kurios/article/view/34/48.

Sitorus, Herowati. "Refleksi Teologis Kitab Yeremia Tentang Pesan Sang Nabi Bagi Orang-Orang Buangan." BIA': Jurnal Teologi dan Pendidikan Kristen Kontekstual 1, no. 2 (2018): 267-280. http://www.jurnalbia.com/index.php/bia/article/view/58.

Sriyanto, Bambang, and Thomy Sanggam Hasiholan Sihite. "Peran Gereja Dalam Pembinaan Kerohanian Remaja Di Gereja Pantekosta Di Indonesia Kota Palangka Raya." KHARISMATA: Jurnal Teologi Pantekosta 2, no. 2 (2020): 101-112. http://www.e- 
journal.stajember.ac.id/index.php/kharismata/article/view/32/pdf.

Sugiyono, Sugiyono. Metode Penelitian Kuantitatif. Bandung: AlfaBeta, 2018.

Susanta, Yohanes Krismantyo. "Menjadi Sesama Manusia' Persahabatan Sebagai Tema

Teologis Dan Implikasinya Bagi Kehidupan Bergereja." DUNAMIS: Jurnal Teologi dan Pendidikan Kristiani 2, no. 2 (2018): 103-118. https://sttintheos.ac.id/ejournal/index.php/dunamis/article/view/169/132.

Sutoyo, Daniel. “Analisis Historis Terhadap Teologi Gerakan Pentakostalisme." DUNAMIS: Jurnal Teologi dan Pendidikan Kristiani 2, no. 2 (2018): 167-196.

Veldhuis, Henri. Kutahu Yang Kupercaya. Jakarta: BPK Gunung Mulia, 2010.

Whidmurni, Whidmurni. "Penelitian Kuantitatif." Pemaparan Metode Penelitian Kuantitatif 2, no. 16 (2017): 1-16. http://repository.uinmalang.ac.id/1985/2/1985.pdf.

Williams, Andrew. "Spiritual Landscapes of Pentecostal Worship, Belief, and Embodiment in a Therapeutic Community: New Critical Perspectives." Emotion, Space and Society 19, no. 1 (2016): 45-55. 